\title{
Saúde Pública, Redução de Danos e a Prevenção das Infecções de Transmissão Sexual e Sanguínea: revisão dos principais conceitos e sua implementação no Brasil
}

\author{
Public Health, Damage Containment and the Prevention \\ of Blood-borne and Sexually Transmitted Infections: \\ a review of the core concepts and their implementation in Brazil
}

Lucília de Almeida Elias ${ }^{1}$ Francisco Inacio Bastos ${ }^{2}$
${ }^{1}$ Centro de Saúde Escola Germano Sinval Faria, Escola Nacional de Saúde Pública, Fundação Oswaldo Cruz (Fiocruz). Rua Leopoldo Bulhões 1480/Térreo, Manguinhos. 21041-210 Rio de Janeiro RJ. luciliaelias@ensp.fiocruz.br ${ }^{2}$ Instituto de Comunicação e Informação Científica e Tecnológica, Fundação Oswaldo Cruz

\begin{abstract}
This article assesses the historical context and the conceptual frame of setting up damage containment programs in the field of public health, with special emphasis on the Brazilian experience. The survey seeks to assess the relevance of such programs in the ongoing efforts to curb the spread of blood-borne and sexually transmitted infections, especially AIDS and hepatitis C. Findings from both the Brazilian and the international literature demonstrate that practical damage containment initiatives tend to be more effective when integrated with other public health measures based on common goals. Damage containment initiatives, aligned with the basic principles of public health do not limit themselves to a priori models or health care per se. They encompass a variety of pragmatic measures based on public policies and should be in line with the demands of the communities since the moment of their inception and implemented in the context of full partnership with such communities.
\end{abstract}

Key words Damage containment, Public Health, Substance abuse, Blood-borne pathogens, Sexually Transmitted Diseases
Resumo Este artigo aborda o contexto histórico e o marco conceitual da implantação dos programas de redução de danos no campo da saúde pública, com ênfase nos programas brasileiros. A presente revisão teve como objetivo principal investigar a pertinência atual de tais programas no enfrentamento das infecções de transmissão sexual e sanguínea, em especial, a AIDS e a hepatite C. Os resultados sistematizados pela literatura nacional e internacional indicam que as ações práticas de redução de danos são mais efetivas quando integradas a outras medidas de saúde pública, guiadas por princípios em comum. Iniciativas de redução de danos afinadas com princípios de saúde pública não se prendem a modelos, nem se esgotam em cuidados de saúde propriamente ditos. Abrangem diversas modalidades de ações pragmáticas, com base em políticas públicas, devem estar em sintonia com a comunidade desde seu planejamento, $e$ serem executadas em parceria com esta.

Palavras-chave Redução de danos, Saúde Pública, Abuso de substâncias, Patógenos de transmissão sanguínea, Doenças Sexualmente Transmissíveis 


\section{Introdução}

A Redução de Danos (RD) é definida como conjunto estratégico de medidas de saúde pública destinadas a minimizar as consequências adversas do uso prejudicial de álcool e drogas ${ }^{1}$. Estas medidas se traduzem em alternativas de uso que envolvam menores riscos e danos para os consumidores de tais substâncias e para a coletividade. Riscos são chances probabilísticas de suscetibilidade a agravos e doenças, em função da exposição de indivíduos a agentes agressores (ou protetores) $)^{2}$. A formalização do conceito de risco foi central ao processo de elaboração teórica da epidemiologia moderna, que tem lugar em 1946-65, seguindo-se a um período de ampliação das concepções de saúde pública e práticas sanitárias ${ }^{2}$.

A proposta de eliminar riscos constitui uma meta consoante com a noção anterior, desde que tal proposta seja factível (e, em determinadas circunstâncias, desejável), impossibilidade evidente em relação a determinados comportamentos, ao menos em alguns contextos e momentos históri$\cos ^{3}$. É possível que alguém que venha fazendo uso problemático de álcool e/ou drogas possa se manter inteiramente abstinente (a depender do psiquismo do indivíduo e das circunstâncias em que o mesmo está inserido). Na esfera da população e da comunidade, entretanto, tal meta enquanto meta coletiva não é factível (e não necessariamente desejável, para alguns segmentos sociais), e tem resultado antes na imposição de leis draconianas, que violam os direitos humanos, sem contribuir de fato para a redução dos danos e riscos em pauta.

Os usuários de drogas ilícitas constituem um segmento posto à parte dos direitos de cidadania conquistados pela sociedade. A violação destes direitos acontece em vários países e se dá em níveis diversos: tais violações impossibilitam a inserção e/ou a permanência na cadeia produtiva daqueles que procedem ao registro, obrigatório por lei, para tratamento nos serviços públicos de saúde (por exemplo, na Rússia) ${ }^{4}$; precipita o rompimento de seus vínculos sociais, e familiares, uma vez que os indivíduos são humilhados publicamente (por exemplo, na China) ${ }^{5}$, e presos de modo arbitrário, sofrendo tortura e maus tratos (como relatado no Camboja e Paquistão) . $^{5}$

Assassinatos de jovens negros e pobres nas favelas brasileiras são quase sempre veiculados pela mídia em associação direta ou indireta com o consumo ou o tráfico de drogas. É como se o desrespeito aos direitos humanos mais funda- mentais fosse socialmente justificado quando se trata destas pessoas. O secretário de segurança do Rio de Janeiro, entrevistado em horário nobre (Jornal Nacional, 23 de março de 2009), responsabilizou os usuários de drogas pela violência deflagrada por incursões policiais nas favelas da cidade, "porque a disputa por pontos de venda é por dinheiro, e se ninguém comprasse, não haveria o que disputar". Ainda que, inegavelmente, demanda e oferta tendam a se equilibrar segundo os cânones da teoria econômica neoclássica, tal formulação nada acrescenta à compreensão e ao enfrentamento dos determinantes estruturais da violência.

A consequência de tais ações, pautadas por uma "política criminal com derramamento de sangue", soma-se aos outros danos à saúde e sociais causados pelo uso prejudicial de drogas, dificultando (ou mesmo, inviabilizando) a adoção de medidas de saúde pública visando a reduzi-los?

O governo brasileiro, em sintonia com os movimentos sociais, tem envidado esforços para se contrapor à violação dos direitos dos usuários de drogas, através de mudanças na legislação e de ações de conscientização. Desde os anos '90 o Brasil apoia, do ponto de vista da sua legislação e formulação de políticas públicas, o movimento de redução de danos (RD) e preconiza a diversidade de abordagens nas intervenções de cuidado, seja na opção de tratamento como alternativa à prisão (para pessoas que usam drogas de modo indevido), seja no acesso universal à medicação requerida por aquelas infectadas pelo HIV (algumas delas afetadas pela síndrome clínica, ou AIDS), independentemente de fazerem uso ou não de substâncias psicoativas ilícitas, correspondendo hoje a cerca de $60 \%$ dos usuários de drogas vivendo com o HIV em todo o mundo em tratamento com medicamentos antiretrovirais 8 .

Há importantes mudanças em curso na política de drogas em outros países da América do Sul (como Argentina, Bolívia, Equador e Uruguai $)^{5}$, principal região produtora de coca/cocaína no mundo, especialmente na região Andina. Espera-se que tais iniciativas (em curso) redundem em políticas públicas menos centralizadoras e autoritárias nesta região, e contribuam para promover uma reforma substancial nas suas políticas de drogas 9 . A estratégia de RD necessita de suporte político e legislativo para funcionar adequadamente $^{10}$, o que compreende intervenções fundamentais, básicas, de captação para os serviços de saúde de um contingente de usuários habitualmente "invisíveis" para os mesmos. Re- 


\section{Método}

O presente artigo procede uma revisão bibliográfica da literatura internacional referente a programas e pesquisas em redução de danos na interface com a saúde pública, publicados no período 1998-2009, além de artigos clássicos, indispensáveis à compreensão histórica e/ou conceitual do tema.

Foram consultadas diferentes bases bibliográficas e de informações correlatas (como citações e fatores de impacto) como: Medline, Science Direct, Scopus e Web of Science, utilizando-se como descritores: redução de danos (harm reduction), saúde pública (public health), abuso de drogas (substance abuse) e Brasil. Além disso, foram utilizadas as bibliotecas pessoais dos autores, essenciais na busca de referências não indexadas nas bases supracitadas.

A ampla maioria das referências sobre o tema, sobre as quais há inúmeras revisões, aborda a questão sob a óptica exclusiva da Redução de danos em si, com escassa inter-relação com a temática mais ampla da saúde pública. O propósito presente foi, no entanto, distinto. Ainda que reconhecendo que um campo que lida com uma população estigmatizada e criminalizada, com ações que têm lugar em um contexto pouco simpático, quando não francamente hostil, há uma inevitável tendência de que as publicações se voltem para dentro do próprio campo, nossa opção foi privilegiar o diálogo mais amplo com a saúde pública. Nesse sentido, em lugar das habituais tensões e conflitos, que, inegavelmente, persistem, o artigo aposta na interação produtiva e mutuamente fecunda entre Redução de danos e saúde pública lato sensu.

\section{Histórico}

O conceito de RD tem origem no Reino Unido, em 1926, com as recomendações de uma comissão interministerial presidida pelo Secretário da Saúde e presidente do Royal College of Physici-

ans, Sir Humphrey Rolleston \% o Relatório Rolleston ${ }^{11}$. O direito à prescrição regular de opiáceos (produtos derivados do ópio, matéria prima da heroína e substâncias correlatas, então em voga no Reino Unido) a usuários destas drogas, sob determinadas condições, foi estabelecido como prática médica legítima a partir deste Relatório. Esta prescrição incluía o manejo da síndrome de abstinência e casos em que a interrupção do uso da droga não pudesse se dar de modo seguro para o usuário ou impossibilitasse o curso normal e produtivo de sua vida ${ }^{12}$.

Tais recomendações nortearam a política britânica de "prescrição e proibição" de drogas, particularmente a heroína, nos 40 anos seguintes: prescrição médica nas condições mencionadas, proibição - com consequências legais - do uso recreativo e do tráfico de drogas. Nos anos '60 esta prática de prescrever drogas sob orientação médica ficou restrita a médicos licenciados pelo Home Office britânico, medida justificada pelo aumento do consumo de drogas verificado à época, apesar das substâncias em pauta serem basicamente os derivados da cannabis (como a maconha e o haxixe), as anfetaminas e o LSD (ácido lisérgico), mais do que propriamente a heroína (ou outras drogas opiáceas). Desde a década de '70, a ênfase tem sido dada a tratamentos de substituição (da heroína por outras substâncias, ministradas por via oral e com efeito psicoativo desprezível), com a prescrição de metadona (ou, menos comumente, da buprenorfina $)^{13}$. Atualmente, a prescrição de heroína para pessoas que usam esta substância vem sendo objeto de acalorados debates, e se restringe a um pequeno grupo de experiências piloto, na Inglaterra e em outros países europeus, como Dinamarca, Suécia e Suíça $\mathrm{a}^{14}$.

\section{Ações em RD: os exemplos dos programas de troca de seringas e das terapias de substituição}

O objetivo principal dos programas de metadona é a estabilização da vida do paciente e a redução de riscos e danos - uma vez que a evolução para a abstinência se dá numa minoria dos casos. Estudo recente ${ }^{15}$ com profissionais de saúde e usuários destes programas no estado de Illinois, EUA, mostrou uma discrepância de expectativas em relação a estes. Enquanto os profissionais consideravam o tratamento um paliativo, descrevendo suas metas de longo prazo (como a abstinência) como irrealistas, os usuários não excluíam a meta de abstinência, preferindo abor- 
dagens que não visassem apenas às consequências do uso de drogas, mas também à natureza da relação (problemática) estabelecida por eles com estas. Resultados de outro estudo, realizado com usuários de drogas injetáveis em Kingston e Toronto, no Canadá ${ }^{16}$, indicam que o risco de infecção pelo HIV pode ser reduzido por meio da participação dos usuários em programas de manutenção com metadona que não tenham a abstinência como pré-requisito para ingresso e/ ou permanência da sua clientela.

Pessoas que usam álcool e drogas de modo prejudicial necessitam de maiores e mais intensos cuidados de saúde do que a população como um todo. Isto porque apresentam, frequentemente, comorbidades clínicas e psiquiátricas, tais como tuberculose, doenças sexualmente transmissíveis, doenças crônicas em geral e depressão ${ }^{17}$. No caso de drogas injetáveis, os riscos imediatos para a saúde se referem à infecção pelo vírus da AIDS (HIV) e a outros vírus de transmissão sexual e sanguínea, especialmente as hepatites virais, além de fungos e bactérias transmissíveis pelo sangue ${ }^{3}$.

Com exceção da África subsaariana, quase 1/ 3 dos novos casos de pessoas infectadas pelo HIV em todo o mundo estão associados ao uso compartilhado de equipamento de injeção contaminado. Pessoas que usam drogas injetáveis são, proporcionalmente, o principal contingente afetado por esta epidemia em países da Europa oriental, da Ásia central e sudeste e do cone sul da América Latina ${ }^{5}$.

Diferentes pesquisas visando avaliar e mensurar o impacto dos Programas de Redução de Danos (PRD) na incidência de infecção pelo HIV e HCV (vírus da hepatite C) têm sido realizadas em diferentes países, como num estudo de coorte de usuários de drogas injetáveis participantes de tais programas em Amsterdã, Holanda ${ }^{18}$. Os resultados sugerem que a efetividade dos PRD depende da adequada integração de diferentes medidas, sendo insuficientes a provisão de metadona ou a troca de seringas usadas (e potencialmente contaminadas) por seringas estéreis, quando feitas de modo independente uma da outra. Os autores deste estudo concluem que programas integrados são fundamentais para que as medidas acima referidas sejam efetivas, sendo desejável ainda a oferta concomitante de cuidados clínicos, sociais e de aconselhamento. PRD são oferecidos pelo Serviço de Saúde de Amsterdã desde 1982, beneficiando cerca de 2700 dos estimados 3500-4000 usuários holandeses que fazem uso de drogas ditas pesadas (como a heroína e a cocaína $)^{18}$.
Outras experiências bem sucedidas de integração de serviços, no âmbito da prevenção e assistência, têm beneficiado usuários de drogas injetáveis vivendo com hepatite $\mathrm{C}^{19-21}$. A hepatite C é uma epidemia global, com prevalência estimada em $3 \%$ da população mundial, ou seja, cerca de 170 milhões de pessoas ${ }^{10,22}$. Estima-se que usuários de drogas injetáveis constituam cerca de $40 \%$ da população carcerária de alguns países, e que a falta de acesso ao equipamento estéril de injeção, entre outros fatores, transforma os presídios em verdadeiras "incubadoras" desta infecção/agravo ${ }^{23}$, o que se soma a outras afecções, como a tuberculose $e^{24}$, e às más condições de vida em geral.

Pessoas que utilizam drogas injetáveis constituem o principal segmento infectado pelo vírus da hepatite $\mathrm{C}$ em quase todo o mundo ${ }^{25}$, cujo enfrentamento, quando existe, tem-se concentrado nas propostas de RD. Mesmo os países que têm políticas estabelecidas quanto à hepatite $\mathrm{C}$, enfrentam maiores dificuldades no controle desta infecção do que no controle da infecção pelo $\mathrm{HIV}$, gerando questionamentos a respeito da efetividade da RD neste caso ${ }^{26,27}$.

Os determinantes de ambas as epidemias incluem a prevalência viral, a infecciosidade dos vírus e a frequência de comportamentos que favoreçam sua transmissão. A transmissão sexual do HCV é rara, e não é epidemiologicamente relevante, ao contrário da transmissão do HIV. Mas comportamentos de risco que oportunizam o contato sanguíneo entre usuários de drogas injetáveis, aliados à maior infecciosidade do $\mathrm{HCV}$, além de sua maior prevalência, explicam algumas das diferenças de efetividade dos PRD com relação a estes dois vírus ${ }^{28}$. Epidemias com prevalências muito elevadas anteriores à implementação das medidas de saúde pública são mais difíceis de se controlar, em virtude das elevadíssimas taxas de infecção, ou, na expressão de Crofts e colaboradores, devido "à força dos números" (título do seu artigo clássico sobre o tema), e da maior infecciosidade do vírus da hepatite $\mathrm{C}$ (HCV) frente ao da AIDS (HIV) ${ }^{28}$.

$\mathrm{O}$ controle da epidemia de hepatite $\mathrm{C}$ requer maiores esforços para reduzir sua incidência do que os despendidos no controle da AIDS, sobretudo na redução do compartilhamento de equipamento de injeção. É necessário o apoio continuado aos PRD existentes, a implantação da troca de seringas em presídios e as pesquisas que contribuam para orientar iniciativas visando à prevenção e à mudança de modos de administração de drogas por via injetável para outras vias ${ }^{28}$. 
A investigação de estratégias visando prevenir a transição para a via injetável por parte de usuários de drogas que ainda não a utilizam é importante, entre outros fatores, porque a infecção pelo vírus da hepatite $\mathrm{C}$ ocorre muito precocemente em pessoas que usam drogas por esta via $^{29,30}$. Existem formas de prevenção combinando redes de apoio e atenção psicossocial, aconselhamento e a mobilização de pares mais experientes, para que enfatizem aos usuários iniciantes a necessidade de evitar práticas que envolvam maiores danos e riscos ${ }^{30}$.

Práticas sexuais menos seguras estão frequentemente associadas ao uso/abuso de substâncias, agregando-se aos riscos de infecção mencionados $^{3}$. Grande número de parceiros sexuais, sexo desprotegido e sexo em troca de drogas ou de dinheiro para adquiri-las constituem comportamentos evidenciados em pesquisa com usuárias de crack residentes no estado de São Paulo, Bra$\mathrm{sil}^{31}$. O perfil socioeconômico de usuários de crack brasileiros ${ }^{32}$ é semelhante ao dos usuários de cocaína injetável: ambos pertencem às camadas mais pobres da população e tendem a trocar sexo por drogas, o que ajudaria a explicar taxas mais elevadas de diferentes infecções entre pessoas que usam crack, em comparação com usuários de cocaína inalada e, especialmente, comparadas às taxas observadas na população geral ${ }^{33}$. Relações sexuais desprotegidas e em troca de drogas, relatadas por adolescentes do sexo feminino em estudo realizado em Porto Alegre, sul do Brasil, se mostraram estreitamente associadas à infecção pelo $\mathrm{HIV}^{34}$. De forma similar, estudo desenvolvido junto a usuárias de drogas afro-americanas residentes no Brooklyn, Nova York ${ }^{35}$, indica que várias infecções sexualmente transmissíveis, dentre as quais a infecção pelo HIV, se mostram endêmicas (alguns diriam que hiperendêmicas) entre estas mulheres. Os resultados sugerem, de acordo com estes pesquisadores, a existência de nichos ("core networks") microssociais de incidência elevada de tais infecções, além dos já conhecidos conglomerados geográficos, onde tais infecções apresentam elevada prevalência de fundo (background prevalence) ${ }^{36}$.

Cabe lembrar que os riscos associados ao comportamento sexual de pessoas que usam álcool e drogas não se restringem àquelas que o fazem de modo prejudicial ou abusivo. O conceito de "modulação do comportamento" foi empregado em análise recente ${ }^{37}$ do comportamento sexual e o uso de substâncias psicoativas (lícitas ou ilícitas) por parte da população urbana brasileira. Estudou-se a relação entre os padrões de utilização de preservativos e outros métodos contraceptivos, e o consumo de álcool e drogas. Os resultados desta análise, realizada com amostra representativa da população urbana brasileira, indicam um "possível efeito modulador das substâncias psicoativas sobre as práticas sexuais de uma faixa expressiva da população geral" 37 .

\section{Programas de Troca de Seringas (PST): breve histórico}

Deve-se ao Relatório Rolleston a inserção no campo da saúde pública do enfrentamento dos problemas associados ao uso prejudicial de drogas e o endosso à prescrição de drogas ilícitas sob supervisão médica. Não obstante, as primeiras ações de RD na acepção moderna do termo, já no contexto da emergência de diferentes doenças infecciosas, foram implementadas inicialmente pelos próprios consumidores. A iniciativa de trocar seringas usadas, e potencialmente contaminadas, por seringas novas/estéreis, partiu de associações de usuários holandeses (Junkiebonden), no enfrentamento de epidemias concomitantes de hepatite B e C nesta população, em Amsterdã, em $1984^{3}$. Registra-se iniciativa similar, em 1982-84, em Edimburgo, Escócia, por ocasião de uma epidemia de infecção pelo HIV e por hepatites $\mathrm{B}$ e $\mathrm{C}^{38}$, sem que se dispusesse ainda de um programa estruturado de RD. A distribuição de seringas estéreis foi viabilizada por uma parceria entre pessoas que utilizavam drogas e proprietários e empregados de uma farmácia local.

Ações pioneiras de RD foram implementadas em diversos contextos por organizações formais e informais de pessoas que utilizavam drogas injetáveis, a partir do reconhecimento do risco potencial de infecção pelo HIV neste contingente da população. $\mathrm{O}$ exame de documentos das décadas de '70 e ' 80 , além de entrevistas realizadas com estas pessoas em algumas cidades da Europa e Austrália, documentam sua influência decisiva nas primeiras intervenções de saúde implantadas com base na $\mathrm{RD}^{39}$.

Tais intervenções ganharam força no enfrentamento da epidemia nos anos ' 80 , com a disponibilização da testagem anti-HIV a partir de 1985 , o que aumentou a visibilidade da epidemia. Programas oficiais de prevenção especificamente dirigidos a usuários de drogas foram formulados e efetivamente implantados em países da Europa, na Austrália e nos Estados Unidos ${ }^{40}$.

O primeiro projeto abrangente contemporâneo em RD, associado ao uso prejudicial de drogas, foi implementado oficialmente na região de 
Mersey (cuja maior cidade é Liverpool), no início da epidemia de AIDS no Reino Unido, em 1986-7 ${ }^{41}$. O risco de infecção pelo HIV secundário ao uso compartilhado do equipamento usado na injeção de drogas concentrou as ações de $\mathrm{RD}$ no fornecimento de equipamento estéril, na prescrição substitutiva de metadona e na busca ativa de pessoas a serem cuidadas nas suas próprias comunidades (outreach work).

Em Mersey, havia uma hierarquia de objetivos a serem cumpridos, claros e simples, que foram, em boa medida, alcançados. Estes objetivos poderiam ser listados nessa ordem: reduções do compartilhamento de material usado na injeção de drogas, da frequência de injeções, do uso de drogas nas ruas e do uso de drogas em geral, e, se possível, o aumento do número e da proporção de pessoas abstinentes. No final dos anos '80, metade da população-alvo havia sido contactada e Liverpool e arredores concentravam um terço das prescrições de metadona de todo o país. O programa contribuiu decisivamente para prevenir a nascente epidemia de AIDS entre usuários de drogas injetáveis na região ${ }^{41}$.

O que aconteceu em Mersey expressa o vínculo estrito entre RD e o trabalho de saúde pública, definido como "esforço organizado da comunidade, por intermédio do governo ou de instituições, para promover, proteger e recuperar a saúde de pessoas e da população, por meio de ações individuais e coletivas" ${ }^{\text {"2 }}$. Uma série de idéias, estruturadas em torno da proposição de um novo modelo de saúde pública, estavam sendo desenvolvidas por ocupantes de cargos estratégicos em Mersey, por ocasião das intervenções supra-mencionadas ${ }^{43}$. O movimento, intitulado nova saúde pública, advogava a necessidade de se promover um equilíbrio entre as ações individuais e a ação coletiva, de modo a facilitar mudanças ambientais e sociais que se refletissem em melhorias no cuidado da saúde. A nova saúde publica e a RD foram movimentos sociais paralelos, coincidentes, histórica e conceitualmente ${ }^{44}$.

Intervenções práticas de maior êxito na prevenção e/ou controle da epidemia de AIDS entre usuários de drogas injetáveis se pautam em princípios fundamentais de saúde pública. O pragmatismo requerido pela urgência e complexidade dos problemas contemporâneos tornou urgente a formulação de respostas oportunas, sempre que possível com defasagem mínima de tempo, de modo a reduzir os danos à saúde e os sociais associados a determinadas práticas. Iniciativas de RD afinadas com princípios de saúde pública não se prendem a modelos, nem se esgo- tam em cuidados de saúde propriamente ditos. São extensivas a diversos tipos de ações pragmáticas, com base em políticas públicas, e devem estar em sintonia com a comunidade desde seu planejamento, e ser executadas em parceria com esta. Alguns exemplos destas iniciativas são: facilitação do acesso legal a equipamento estéril de injeção, busca ativa de pessoas que usam álcool e drogas de forma prejudicial, recepção e acolhimento destas em serviços de saúde adequados às suas necessidades, trabalho com usuários destas substâncias, com seus pares e parceiros sexuais, intervenção em grupos, e articulação de redes de apoio social a estas pessoas ${ }^{44}$.

\section{Perspectivas Contemporâneas em RD}

As iniciativas em RD se expandiram nos últimos vinte anos, trilhando rumos diversos nos países onde foram inicialmente implementadas, e se espalharam para outras partes do mundo. Em 2006, havia mais de 65 países com algum tipo de programa de distribuição de seringas, e 58 países com alguma forma de tratamento substitutivo ao uso prejudicial de drogas (a prescrição de metadona quadruplicou a partir de meados dos anos ' 90$)^{40}$. Os PRD têm apoio governamental em muitos países europeus, na Austrália e, recentemente, na Indonésia, Malásia, Tailândia e China. Já há PRD na Europa Oriental e Central, Ásia e América Latina, impulsionados em parte pela militância e pelo trabalho coletivo, construído e organizado em rede ${ }^{40}$.

A RD obteve apoio das Nações Unidas em vários níveis e por meio de suas diferentes agências: UNAIDS (The Joint United Nations Programme on HIV/AIDS), UNICEF (The United Nations Children's Fund), UNODC (United Nations Office on Drugs and Crime) e Organização Mundial de Saúde (OMS).

\section{Os PRD no Brasil}

A associação entre o uso de drogas injetáveis e a infecção pelo HIV foi relatada em 114 países, dos 134 que documentaram esta infecção em $1999^{45}$. Em 2001, casos de AIDS entre usuários de drogas injetáveis na América Latina, correspondiam a $34,3 \%$ do total registrado no Cone Sul (Argentina, Chile, Paraguai e Uruguai); 20,2\% no Brasil; 2,8\% no Caribe Latino (Cuba, Haiti, Porto Rico e República Dominicana); 0,9\% na América Central (Belize, Costa Rica, El Salvador, Guatemala, Honduras, Nicarágua e Panamá); 0,6\% no México e 0,2\% na região dos Andes (Bolívia, Colômbia, Equador, Peru e Venezuela ${ }^{46}$. 
Estudo multicêntrico em 13 cidades da América Latina, apoiado pela $\mathrm{OMS}^{47}$, em 1989-90, contribuiu para implantar métodos renovados de pesquisa na região, subsidiar políticas públicas e estabelecer redes internacionais de cooperação. O debate público, nacional e internacional, acerca de medidas (de saúde pública) visando conter a disseminação do HIV conferiu nova dimensão à questão das drogas injetáveis ${ }^{48}$.

Um dos primeiros estudos epidemiológicos sobre a transmissão do HIV entre pessoas que utilizam drogas injetáveis na América Latina foi realizado em 1991, em Santos, São Paulo, com parte do estudo supramencionado ${ }^{49}$. Santos era à ocasião a cidade brasileira com a maior taxa de incidência de infecção por HIV do país, e nela a proporção de usuários de drogas injetáveis entre os casos de AIDS era de 52\%. Ou seja, os usuários de drogas injetáveis em atividade \% estimados, à época, em menos de $1 \%$ da população total - correspondiam a mais da metade dos casos de AIDS registrados naquela cidade. O estudo fez com que fosse recomendada, aos serviços de saúde pública, atenção específica a estas pessoas, dada sua importância na disseminação da epidemia local.

Teve lugar justamente em Santos a primeira tentativa de implantar um Programa de Troca de Seringas (PTS) no Brasil, em 1989. A proposta de trocar seringas usadas por novas (estéreis) foi, entretanto, interpretada como "estímulo ao consumo de drogas" 9 , tendo sido embargada judicialmente pelo Ministério Público do Estado de São Paulo, que entrou com uma ação civil e criminal contra os organizadores do programa e o governo da cidade.

Apenas em 1995 foi de fato implantado o primeiro PTS no Brasil, em Salvador, Bahia. O programa foi possível graças à parceria entre o Centro de Estudos e Tratamento em Atenção ao Uso de Drogas (CETAD), a Escola de Medicina e a Universidade Federal da Bahia, apoiados pelos governos estadual e municipal ${ }^{50}$. Este programa foi pioneiro na América do Sul, onde atualmente, além do Brasil, apenas a Argentina apóia oficialmente tais programas.

A América do Sul é uma região de desigualdades pronunciadas entre as classes sociais, com populações vulneráveis a diferentes agravos e doenças ${ }^{51}$. A análise de dados coletados ao longo de dez anos (1995-2004), na cidade de Porto Alegre, sul do Brasil, evidenciou que usuários de drogas injetáveis, homens que têm sexo com homens e usuários de crack são mais vulneráveis à infecção pelo HIV do que o restante da população.
Pobreza, baixa escolaridade e o uso compartilhado de drogas injetáveis se mostraram fatores de risco centrais para a infecção pelo HIV naquela cidade, com o recente acréscimo dos riscos adicionais associados ao uso de crack fumado ${ }^{33}$.

Atualmente a taxa de infecção pelo HIV na população brasileira é de $0,6 \%$, com relativa concentração, a partir dos anos ' 90 , em subpopulações particularmente vulneráveis, tais como homens que fazem sexo com outros homens que são usuários de drogas injetáveis, mulheres que usam drogas injetáveis e usuários de drogas injetáveis em situação de extrema pobreza ${ }^{52}$.

A epidemia de AIDS no Brasil é um compósito de diversas subepidemias regionais. O país tem dimensões continentais, e apresenta diferenças regionais importantes em seu desenvolvimento socioeconômico e na sua composição demográfica, entre outros aspectos ${ }^{53}$. Desde o início da epidemia, nos anos ' 80 , tem havido variações de incidência e prevalência das epidemias regionais e locais, nas diferentes regiões geográficas e subpopulações do país.

A infecção pelo HIV entre pessoas que usam drogas injetáveis seguiu inicialmente a rota principal do tráfico de cocaína, da fronteira oeste para os portos principais do sudeste $e^{54,55}$. Foi nesta região - sudeste industrializado, principalmente no estado de S. Paulo e, mais recentemente, em cidades ao longo da região costeira deste estado até o sul do Brasil - que usuários de drogas injetáveis desempenharam um papel central na disseminação da epidemia ${ }^{56}$. Cabe lembrar que estas pessoas pertencem, em geral, às classes sociais mais pobres e menos escolarizadas da população, mas estão concentradas nas regiões mais afluentes do pais $^{57,58}$.

No final dos anos ' 90 , a proporção de usuários de drogas injetáveis entre as pessoas infectadas pelo HIV na costa sul do Brasil aumentou de forma expressiva, assim como o tráfico e o consumo de cocaína na região, correspondendo a cerca de $50 \%$ do total de casos registrados em algumas cidades costeiras do estado de Santa Catarina e Rio Grande do Sul ${ }^{58}$. Estes achados, segundo análise recente ${ }^{59}$, podem contribuir para explicar a disseminação rápida e continua da epidemia entre mulheres (muitas delas parceiras sexuais de pessoas que usam drogas injetáveis) e da transmissão vertical (da mãe para o bebê) nesta região, bem como o declínio menos expressivo das mortes relacionadas à infecção pelo HIV, em relação a outras regiões do país, em função do contexto de pobreza e discriminação em que estão inseridos os usuários de drogas injetáveis e 
suas redes sociais, mesmo num país que conta com acesso universal à terapia antirretroviral.

Assim, no enfrentamento da "sinergia" constituída pelo tráfico e pelo consumo de cocaína e de expansão da epidemia de AIDS na população de usuários de drogas, "desde meados dos anos '90 o Brasil incluiu a estratégia de redução de danos em sua agenda de saúde pública" ${ }^{53}$.

Dados disponíveis em novembro de $2006^{60}$ estimaram em torno de 150 o número de programas de troca de seringas em funcionamento no Brasil em diferentes regiões, estados e municípios. Estes programas foram implantados por universidades, instituições governamentais, como secretarias de saúde, e organizações não governamentais. $\mathrm{O}$ apoio ao movimento de $\mathrm{RD}$ tem crescido no país, apesar de restrições ao financiamento dos programas, falta de experiência gerencial em muitos deles e um processo acidentado de descentralização de ações e recursos ${ }^{61}$. É preciso que tais programas sejam monitorados e avaliados regularmente, que bancos de dados regionais e locais sejam implantados e permanentemente atualizados e revisados, e que se estabeleçam incentivos e sanções reforçando a responsabilização por estas iniciativas ${ }^{50}$.

Estudo recente ${ }^{62}$ mapeou e descreveu 11 programas de RD da região metropolitana de Porto Alegre, sul do Brasil, no período 2004-2006, comparando os dados encontrados com mapeamento datado de 2003, na mesma região. Ambos os estudos indicam características comuns aos programas, que dificultam as ações de cuidado pres- tadas por estes. Destacam-se a precariedade do vínculo profissional das equipes de trabalho, a prestação voluntária de serviços, como base de apoio a muitas das ações mencionadas, e a influência das mudanças de gestão \% municipal e estadual \% sobre os recursos humanos e os financeiros dos programas enquanto fatores que afetam a continuidade e a efetividade dos mesmos.

\section{Considerações finais}

As iniciativas de ordem prática, implementadas na interseção dos campos definidos pela saúde pública e pela $\mathrm{RD}$, ultrapassam fronteiras teóricas em busca de condições mais propícias à vida: “a vida, por trás das quantidades, o grande desafio da epidemiologia 'normal' de nossos dias"63.

A plena integração das ações de RD às iniciativas de saúde pública ainda está, em grande medida, por se fazer, e, quando existe, como nos recém-abertos CAPS-AD (Centros de Atenção Psicossocial a Usuários de Álcool e Drogas), ainda está por ser devidamente avaliada. Não resta dúvida, entretanto, que as ações de redução de danos devem ser plenamente integradas às ações latu senso em saúde pública, deixando para trás uma crônica vitoriosa, mas amarga, de conflitos e confrontos, em prol do diálogo e do crescimento mútuos, sempre em respeito aos direitos humanos e em prol da população de usuários de drogas, seus familiares e próximos.

\section{Colaboradores}

LA Elias e FI Bastos participaram igualmente de todas as etapas de elaboração do arquivo. 


\section{Referências}

1. Brasil. Decreto no 6.117 de 22 de maio de 2007. Dispõe sobre as medidas para redução do uso indevido de álcool e sua associação com a violência e criminalidade. Diário Oficial da União 2007; 23 maio.

2. Ayres JRCM. Sobre o risco - para compreender a epidemiologia. São Paulo: Hucitec; 2002.

3. Bastos FI. AIDS na terceira década. Rio: Ed. Fiocruz; 2006.

4. Bobrova N, Rhodes T, Power R, Alcorn R, Neifeld E, Krasiukov N, Latyshevskaia N, Maksimova S. Barriers to accessing drug treatment in Russia: a qualitative study among injecting drug users in two cities. Drug Alcohol Depend 2006; 82(Supl. 1):57-63.

5. Open Society Institute. At what cost? HIV and Human Rights Consequences of the global "war on drugs". New York: Open Society Institute; 2009.

6. Batista N. Política Criminal com Derramamento de Sangue. Discursos Sediciosos 1998; 3(5-6):77-94.

7. Kessler F, Pechansky F. Uma visão psiquiátrica sobre o fenômeno do crack na atualidade. Rev Psiquiatr RS 2008; 30(2):96-98.

8. Aceijas C, Oppenheimer E, Stimson GV, Ashcroft RE, Matic S, Hickman M. Antiretroviral treatment for injection drug users in developing and transitional countries 1 year before the end of the "Treating 3 million by 2005. Making it happen. The WHO strategy" (“3 by 5”). Addiction 2006; 101(9):1246-1253.

9. Bastos FI, Caiaffa W, Rossi D, Vila M, Malta M. The children of mama coca: Coca, cocaine and the fate of harm reduction in South America. Int J Drug Policy 2007; 18(2):99-106.

10. Madden A, Cavallieri W. Hepatitis C prevention and true harm reduction. Int $J$ Drug Policy 2007;18(5):335-337.

11. Sheldon T. More than a quick fix. BMJ 2008 ; 336(7635):68-69.

12. Brasil. Ministério da Saúde (MS). Coordenação Nacional de DST e AIDS. Manual de Redução de Danos. Brasília: Ministério da Saúde (MS); 2001.

13. Amato L, Davoli M, Perucci CA, Ferri M, Faggiano F, Mattick RP. An overview of systematic reviews of the effectiveness of opiate maintenance therapies: available evidence to inform clinical practice and research. J Subst Abuse Treat 2005; 28(4):321-329.

14. Rehm J, Fischer B. Should heroin be prescribed to heroin misusers? BMJ 2008; 336(7635):70-73.

15. Järvinen M. Approaches to methadone treatment: harm reduction in theory and practice. Sociol Health Illn 2008; 30(7):975-991

16. Millson P, Challacombe L, Villeneuve PJ, Strike CJ, Fischer B, Myers T, Shore R, Hopkins S. Reduction in injection-related HIV risk after 6 months in a low-threshold methadone treatment program. AIDS Educ Prev 2007; 19(2):124-136.

17. New York State Department of Health Aids Institute in collaboration with the Johns Hopkins University Division of Infectious Diseases. HIV Clinical Resource. Clinical Guidelines. Updated oct 2006. [acessado 2008 fev 14]. Disponível em: http://www. hivguidelines.org/Content.aspx.
18. Van Den Berg C, Smit C, Van Brussel G, Coutinho R, Prins M. Full participation in harm reduction programmes is associated with decreased risk for human immunodeficiency virus and hepatitis $\mathrm{C}$ virus: evidence from the Amsterdam Cohort Studies among drug users. Addiction 2007; 102(9):1454-1462.

19. Sylvestre DL, Zweben JE. Integrating HCV services for drug users: A model to improve engagement and outcomes. Int J Drug Policy 2007; 18(5):406-470.

20. Birkhead GS, Klein SJ, Candelas AR, O'Connell DA, Rothman JR, Feldman IS, Tsui DS, Cotroneo RA, Flanigan CA. Integrating multiple programme and policy approaches to hepatitis $\mathrm{C}$ prevention and care for injection drug users: a comprehensive approach. Int J Drug Policy 2007; 18(5):417-425.

21. Grebely J, Genoway K, Khara M, Duncan F, Viljoen M, Elliott D, Raffa JD, DeVlaming S, Conway B. Treatment uptake and outcomes among current and former injection drug users receiving directly observed therapy within a multidisciplinary group model for the treatment of hepatitis $\mathrm{C}$ virus infection. Int J Drug Policy 2007; 18(5):437-443.

22. World Health Organization (WHO). Hepatitis C Factsheet No 164 2000. [acessado 2008 fev 14]. Disponível em: http://www.who.int/mediacentre/factsheets

23. Vumbaca G. International prisons - the need for change. The National Magazine on Alcohol, Tobacco and other Drugs 2005; 2(3):10-11.

24. Larouzé B, Sánchez A, Diuana V. Tuberculosis behind bars in developing countries: a hidden shame to public health. Trans R Soc Trop Med Hyg 2008; 102(9):841-842.

25. Aceijas C, Rhodes T. Global estimates of prevalence of HCV infection among injecting drug users. Int J Drug Policy 2007; 18(5):352-358.

26. Hagan H. HCV Synthesis Project: Preliminary analyses of HCV prevalence in relation to age and duration of injection. Int J Drug Policy 2007; 18(5):341351.

27. Mateu-Gelabert P, Treloar C, Calatayud VA, Sandoval M, Zurián JC, Mahler L, Rhodes T, Friedman SR. How can hepatitis $C$ be prevented in the long-term? Int J Drug Policy 2007; 18(5):338-340.

28. Crofts N, Aitken CK, Kaldor JM. The force of numbers: why hepatitis $\mathrm{C}$ is spreading among Australian injecting drug users while HIV is not. Med J Aust 1999; 170(5):220-221.

29. Garfein RS, Vlahov D, Galai N, Doherty MC, Nelson KE. Viral infections in short-term injection drug users: the prevalence of the hepatitis $\mathrm{C}$, hepatitis $\mathrm{B}$, human immunodeficiency, and human T-lymphotropic viruses. Am J Public Health 1996; 86(5):655661.

30. Bastos FI. O som do silêncio da Hepatite C. Rio de Janeiro: Ed Fiocruz; 2006.

31. Nappo AS, Sanchez ZM, Oliveira LG, Santos AS, Coradete Júnior J, Pacca JCB, Lacks V. Comportamento de risco de mulheres usuárias de crack em relação às DST/ AIDS. São Paulo: Centro Brasileiro de Informações sobre Drogas Psicotrópicas; 2004.

32. Duailibi LB, Ribeiro M, Laranjeira R. Profile of cocaine and crack users in Brazil. Cad Saude Publica $2008 ; 24(4): 545-557$. 
33. Pechansky F, Woody G, Inciardi J, Surratt H, Kessler F, Von Diemen L, Bumaguin DB. HIV seroprevalence among drug users: an analysis of selected variables based on 10 years of data collection in Porto Alegre, Brazil. Drug Alcohol Depend 2006; 82(1):109-113.

34. Bassols MAS. Adolescência e infecção pelo HIV: situação de risco e proteção, auto-estima e sintomatologia psiquiátrica [dissertação]. Porto Alegre: Universidade Federal do Rio Grande do Sul; 2003.

35. Miller M, Liao Y, Wagner M, Korves C. HIV, the clustering of sexually transmitted infections, and sex risk among African American women who use drugs. Sex Transm Dis 2008; 35(7):696-702.

36. Singer M, Stopka T, Siano C, Springer K, Barton G, Khoshnood K, Gorry de Puga A, Heimer R. The social geography of AIDS and hepatitis risk: qualitative approaches for assessing local differences in sterile-syringe access among injection drug users. Am J Public Health 2000; 90(7):1049-1056.

37. Bastos FI, Cunha CB, Bertoni N. Use of psychoactive substances and contraceptive methods by the Brazilian urban population, 2005. Grupo de Estudos em População, Sexualidade e Aids. Rev Saude Publica 2008; 42(1):118-126.

38. Copeland L, Budd J, Robertson JR, Elton RA. Changing patterns in causes of death in a cohort of injecting drug users, 1980-2001. Arch Intern Med 2004; 164(11):1214-1220.

39. Friedman SR, de Jong W, Rossi D, Touzé G, Rockwell R, Des Jarlais DC, Elovich R. Harm reduction theory: Users'culture, micro-social indigenous harm reduction, and the self-organization and outsideorganizing of users'groups. Int J Drug Policy 2007; 18(2):107-117.

40. Stimson GV. Harm Reduction - Coming of Age: a local movement with global impact. Int J Drug Policy 2007; 18(3):67-69.

41. O'Hare P. Merseyside, the first harm reduction conferences, and the early history of harm reduction. Int J of Drug Policy 2007; 18(2):141-144.

42. Scliar M. Do mágico ao social: trajetória da saúde pública. São Paulo: SENAC; 2005.

43. Ashton J, Seymour H. The new public health. London: Open University Press, Milton Keynes; 1988.

44. Rhodes T. The 'risk environment': a framework for understanding and reducing drug-related harm. Int J Drug Policy 2002; 13(2):85-94.

45. Needle R, Ball A, Des Jarlais D, Whitmore C, Lambert E. The global research network on HIV prevention in drug-using populations (GRN) 1998-2000: trends in the epidemiology, ethnography, and prevention of HIV/Aids in injection drug users. In: 2000 Global Research Network Meeting on HIV Prevention in Drug Using Populations. Washington DC: Third Annual Meeting Report, NIDA; 2001.

46. Rodriguez CM, Marques LF, Touzé G. HIV injection drug use in Latin America. AIDS 2002; 16(3):34-41.

47. World Health Organization (WHO). WHO collaborative study group on drug abuse: an international comparative study of HIV prevalence and risk behavior among drug injectors in 13 cities. Bull Narc 1993; 45(1):19-46.

48. Hacker MA, Malta M, Enriquez M, Bastos FI. Human immunodeficiency virus, AIDS, and drug consumption in South América and the Caribbean: Epidemiological evidence and initiatives to curb the epidemic. Rev Panam Salud Publica 2005; 18(4-5):303-313.
49. de Carvalho HB, Mesquita F, Massad E, Bueno RC, Lopes GT, Ruiz MA, Burattini MN. HIV and infections of similar transmission patterns in a drug injectors community of Santos, Brazil. J Acquir Immune Defic Syndr Hum Retrovirol 1996; 12(1):84-92.

50. Fonseca EM, Ribeiro JM, Bertoni N, Bastos FI. Syringe exchange programs in Brazil: Preliminary assessment of 45 programs. Cad Saude Publica 2006; 22(4):761-770.

51. Comissão Nacional sobre Determinantes Sociais da Saúde (CNDSS). As Causas Sociais das Iniquidades em Saúde no Brasil. Rio: Editora Fiocruz; 2008.

52. Ferreira AD, Caiaffa WT, Bastos FI, Mingoti AS, Projeto AjUDE-Brasil II. Profile of male Brazilian injecting drug users who have sex with men. Cad Saude Publica 2006; 22(4):849-860.

53. Bastos FI, Nunn A, Hacker MA, Malta M, Szwarcwald CL. AIDS in Brazil: The Challenge and the Response. In: Celentano DD, Beyrer C, editors. Public Health Aspects of HIV/AIDS in Low and Middle Income Countries. New York: Springer; 2008. p. 629-654.

54. Barcellos C, Bastos FI. Redes sociais e difusão da AIDS no Brasil. Boletín de la Oficina Sanitaria Panamericana (OSP) 1996; 121(1):11-24.

55. Bastos FI, de Pina FM \& Szwarcwald CL (2002). The social geography of HIV/AIDS among injection drug users in Brazil. Int J Drug Policy 2002; 13(2):137-144.

56. Hacker MA, Leite IC, Renton A, Torres TG, Gracie $\mathrm{R}$, Bastos FI. Reconstructing the AIDS epidemic among injection drug users in Brazil. Cad Saude Publica 2006; 22(4):751-760.

57. Kalichman A. AIDS and intravenous drug use (IVDU) in Brazil. In: Monteiro MG, Inciardi JA, editors. United States Binational Research. São Paulo: Cebrid; 1993. p. 49-61.

58. Fonseca MG, Castilho EA. Os casos de Aids entre usuários de drogas injetáveis. Brasil, 1980-1997. Boletim Epidemiológico-AIDS 1997; X(3):6-14

59. Hacker MA, Leite I, Friedman SR, Carrijo RG, Bastos FI. Poverty, bridging between injecting drug users and the general population, and "interiorization" may explain the spread of HIV in southern Brazil. Health Place 2009; 15(2):514-519.

60. Brazil. Brazilian Ministry of Health. The Brazilian Response to HIV/AIDS. Brasília: Ministry of Health; 2006.

61. Fonseca EM, Nunn A, Souza-Junior PB, Bastos FI, Ribeiro JM. Decentralization, AIDS, and harm reduction: the implementation of public policies in Rio de Janeiro, Brazil. Cad Saude Publica 2007; 23(9):2134-2144.

62. Nardi HC, Rigoni RQ. Mapeando programas de redução de danos da Região Metropolitana de Porto Alegre, Rio Grande do Sul, Brasil. Cad Saude Publica 2009; 25(2):382-392.

63. Ayres JCMR. Epidemiologia e emancipação. S. Paulo: Hucitec; 1995.

Artigo apresentado em 19/06/2009

Aprovado em 23/01/2010

Versão final apresentada em 05/02/2010 